\title{
Ultrastructural Evidence for GABAergic Brain Stem Projections to Spinal Motoneurons in the Rat
}

\author{
J. C. Holstege \\ Department of Anatomy, Erasmus University Medical School, 3000 DR Rotterdam, The Netherlands
}

In the present ultrastructural study in the rat, it was determined whether GABA was present in projections descending from the ventromedial reticular formation of the lower brain stem to motoneuronal cell groups in the lumbar spinal cord. For this purpose, the anterograde transport of WGA-HRP was combined with the postembedding immunogold technique for GABA, with the advantage that both markers could be visualized simultaneously in a single terminal.

In 4 rats, WGA-HRP was injected in the ventromedial part of the brain stem reticular formation at levels between the rostral inferior olive and the caudal part of the facial nucleus. Vibratome sections were cut from the lumbar spinal cord, reacted for WGA-HRP, and processed for electron microscopy. Ultrathin sections containing the lateral motoneuronal cell groups were cut and treated following the immunogold technique using a polyclonal antibody directed against GABA. It was found that nearly $\mathbf{4 0} \%$ of the terminal profiles that were labeled with WGA-HRP reaction products from the ventromedial brain stem were also labeled for GABA (double labeled). Most of the double-labeled terminals (81\%) were F-type (containing many flattened vesicles), $12 \%$ were G-type (containing many granular vesicles), and $7 \%$ were S-type (containing many spherical vesicles). The majority of the double-labeled terminals contacted proximal dendrites.

It is argued that the descending GABAergic projection produces a general inhibitory effect on spinal motoneurons, counteracting the general facilitation produced by the serotonergic projection derived from the same brain stem area. The balance between the activity of the GABAergic and the serotonergic fibers may set the level of excitability of the spinal motoneurons. The presence of GABA in some of the WGA-HAP-labeled (presumed serotonergic) G-type terminals was interpreted to indicate partial coexistence of GABA and serotonin, supporting the hypothesis that these transmitters are closely related in the descending brain stem projections to spinal motoneurons. The results further indicate that other transmitters are likely to play a part in this gainsetting system, which may be active both during sleep and wakefulness.

\footnotetext{
Received May 4, 1990; revised Aug. 30, 1990; accepted Sept. 5, 1990.

I would like to thank Dr. J. Voogd for reading the manuscript; Mrs. C. M. Bijker-Biemond, Mrs. C. M. H. Bongers, and Mrs. H. Goedknegt for their technical assistance; Mr. E. Dalm for his help with the surgery; and Mrs. P. van Alphen for her help with the photography. This investigation was supported by Grant 900-550-072 from the Foundation for Medical Research MEDIGON, which is subsidized by the Netherlands Research Organization (NWO).

Correspondence should be addressed to J. C. Holstege, Department of Anatomy, P.O. Box 1738, 3000 DR Rotterdam, The Netherlands.

Copyright (C) 1991 Society for Neuroscience 0270-6474/91/1010159-09\$03.00/0
}

The reticular formation of the lower brain stem exerts strong excitatory and inhibitory effects on the activity of spinal motoneurons. It is generally assumed that the inhibitory effect on motoneurons (especially those innervating muscles of the extremities) is relayed through interneurons in the spinal intermediate zone (for review, see Wilson and Peterson, 1981). However, some physiological studies have shown the existence of monosynaptic inhibitory connections between neurons in the medial lower brain stem and spinal motoncurons (Llinas and Terzuolo, 1964; cf. Magoun and Rhines, 1946). Anatomical evidence for direct brain stem projections to motoneuronal cell groups was given by Dahlström and Fuxe (1965) with the histofluorescent technique. They showed the disappearance, below a lesion of the cervical cord, of the serotonergic innervation, including the terminals in the motoneuronal cell groups, with a concomitant increase in the fluorescence of serotonergic cells in the lower brain stem. These findings implied that the direct brain stem projections to motoneurons, which were identified physiologically, were (at least in part) serotonergic. Anatomical tracing studies with the light microscopical (LM) anterograde degeneration technique, using silver impregnation, failed to demonstrate direct projections from the brain stem to spinal motoneuronal cell groups (Kuypers, 1981). They were first shown by means of the LM autoradiographic tracing technique in the cat (Holstcge et al., 1979; G. Holstege and Kuypers, 1982), opossum (Martin et al., 1979), and rat (Jones and Yang, 1985; Martin et al., 1985). The projections to motoneuronal cell groups were found to originate mainly in the caudal raphe nuclei, the adjacent ventral part of the medial reticular formation, and the dorsolateral pons, including the area of the locus coeruleus and subcoeruleus (for review, see Holstege and Kuypers, 1987b).

An ultrastructural study in the rat (Holstege and Kuypers, $1987 \mathrm{a})$ in which the anterograde transport of ${ }^{3} \mathrm{H}$-leucine from the medial reticular formation was combined with the retrograde transport of HRP from the hindleg muscles, showed that the terminals derived from neurons in the ventral part of the medial reticular formation contacted HRP-labeled motoneurons in the lumbar spinal cord. The projections from the ventral part of the medial reticular formation as well as those from the raphe nuclei exhibited 3 different types of terminals: F-type terminals (containing many flattened vesicles), S-type terminals (containing mainly spherical vesicles), and G-type terminals (containing many granular vesicles; Holstege, 1987; Holstege and Kuypers, 1987a). The G-type terminals were found to be serotonergic and/or peptidergic (Pelletier et al., 1981; Ulfhake et al., 1987; for review, see Holstege and Kuypers, 1987b), in agreement with the histofluorescent findings of Dahlström and Fuxe (1965), whereas the transmitters in the F- and S-type terminals remained unknown. Retrograde tracing studies com- 
bined with immunocytochemistry showed that several of the descending brain stem projections were not serotonergic, but presumably contained other transmitters such as various peptides (Hökfelt et al., 1979; Mantyh and Hunt, 1984), AChE (Bowker et al., 1983; Jones et al., 1986), or GABA (Millhorn et al., 1987). However, until now, it could not be determined in which area of the spinal cord the nonserotonergic fibers actually terminated or which transmitter these fibers contained.

Recently, we have combined the anterograde transport of WGA-HRP with the postembedding immunogold technique for GABA (De Zeeuw et al., 1988). This made it possible to address the above questions, because the 2 markers can be visualized simultaneously in a single terminal, revealing both its origin and its transmitter content. By means of this technique, it is shown in the present study that a substantial part of the descending projections from the ventromedial lower brain stem to lumbar motoneuronal cell groups in the rat contains GABA as a transmitter, indicating the existence of a monosynaptic inhibitory (Krnjévic and Schwartz, 1966) projection from the brain stem to spinal motoneurons.

\section{Materials and Methods}

Four Wistar rats (weighing approximately $300 \mathrm{gm}$ ) were deeply anesthetized with pentobarbital $(60 \mathrm{mg} / \mathrm{kg})$, administered by intraperitoneal injection. WGA-HRP ( $5 \%$ in $0.1 \mu \mathrm{l}$ saline) was injected in the ventral part of the medial reticular formation at levels between the caudal part of the facial nucleus and the rostral half of the inferior olive (see Fig. 1). After the rats recovered from the operation, they did not display any signs of discomfort. After $3 \mathrm{~d}$ survival, the animals were reanesthetized with pentobarbital and perfused transcardially with $40 \mathrm{ml}$ saline in phosphate buffer $(0.1 \mathrm{M} ; \mathrm{pH}, 7.3)$ immediately followed by 1 liter $5 \%$ glutaraldehyde in phosphate buffer $(0.1 \mathrm{M} ; \mathrm{pH}, 7.3)$. After perfusion, the brain stem and lumbar spinal cord were dissected. From the brain stem injection site, frozen sections were cut, incubated with diaminobenzidine (DAB; Graham and Karnovsky, 1966), counterstained with cresyl violet, and coverslipped. The 5th and 6 th lumbar segments were cut in slabs $(75 \mu \mathrm{m})$ on a vibratome slicer. These slabs were then reacted for WGA-HRP using tetramethyl benzidine (TMB) as a chromogen (Mesulam, 1978), and the reaction product was stabilized with DABcobalt (Lemann et al., 1985). After rinsing in phosphate buffer containing $8 \%$ glucose, the slabs were postfixed with osmium tetroxide $(1.5 \%$ in phosphate buffer, $\mathrm{pH} 7.3$, containing $8 \%$ glucose). They were then rinsed in distilled water, chemically dehydrated (Muller and Jacks, 1975), and flat embedded in Araldite between Teflon-coated coverslips. After polymerization, the flat-embedded vibratome sections were viewed in the light microscope. The WGA-HRP labeling in the motoneuronal cell groups was examined, and for each rat, the 2 sections with the highest amount of WGA-HRP labeling were selected. They were glued to plastic blocks, and semithin sections were cut and viewed in the light microscope. The blocks were then trimmed to pyramids containing the entire lateral motoneuronal cell group. Ultrathin sections were cut and collected on Formvar-coated nickel grids (200 mesh). These were incubated overnight at $4{ }^{\circ} \mathrm{C}$ with a polyclonal GABA antibody (kindly provided by Dr. R. M. Buijs from the Netherlands Institute for Brain Research, Amsterdam; for specificity tests, see Seguela et al., 1984; Buijs et al., 1987), dissolved in Tris-buffered saline (0.05 $\mathrm{m} ; \mathrm{pH}, 7.6)$ containing $0.1 \%$ Triton X-100 (TBST). After rinsing with TBST (pH, 8.2), the sections were incubated with a goat anti-rabbit antibody, labeled with 15-nm gold particles, and dissolved 1:25 in TBST (pH, 8.2). Then, the sections were rinsed several times, first in TBST ( $\mathrm{pH}, 7.6$ and 8.2), then in distilled water. After counterstaining with lead citrate and uranyl acetate, the ultrathin sections were examined in a Philips 300 electron microscope.

From each of the 4 rats, 2 blocks were used, and from each block, 2 sections were examined (at least $1 \mu \mathrm{m}$ apart); that is, a total of 16 sections, each containing the entire lateral motoneuronal cell groups, were examined. The sections were completely screened for WGA-HRPlabeled terminals, which were recognized by the presence of TMB/DABcobalt reaction products. Other WGA-HRP-labeled structures (mainly axons and occasionally a dendrite or an unidentifiable structure) were not taken into account for the present analysis (for a discussion of these findings, see Holstege, 1987). Each time a WGA-HRP-labeled terminal was encountered, it was determined (Table 1) to which type the terminal belonged (for a description of the different terminal types, see Holstege and Kuypers, 1987a), and it was also determined whether the terminal carried a large number of gold particles (i.e., whether it was GABAergic). This was considered to be the case if the number of gold particles overlying the terminal was at least 8 times the number of gold particles overlying nearby unlabeled structures (terminals and dendrites). In addition, it was determined whether a synapse was present, and if so, the postsynaptic structure was also identified. In the 16 sections analyzed, a total of 505 HRP-labeled terminals were encountered. The results were expressed as percentages per block. These percentages were averaged, and standard deviations were calculated. If the numbcrs obtained per block were too small, the percentages were calculated from total numbers obtained in all 16 sections.

\section{Results}

Light microscopic examination of the WGA-HRP injection site (Fig. 1) showed that the center of the injection was located in the ventromedial part of the lower brain stem at levels between the caudal part of the facial nucleus and the rostral part of the inferior olive. It included the gigantocellular reticular nucleus pars ventralis and pars alpha, as well as part of the paragigantocellular reticular nucleus as described by Andrezik and Beitz (1985). Caudally, the injection site included part of the rostral inferior olive, and more rostrally, the injection site encroached upon the nucleus raphe magnus. Ventromedially, in the periphery of the injection site, some reaction product was seen in the area of the pyramidal tract. However, no labeling was seen in the pyramidal tract caudal to the injection site, indicating that the pyramidal tract fibers had not taken up the WGA-HRP. This is in accordance with observations (Brodal et al., 1983) that WGA-HRP is not taken up by undamaged fibers.

Light microscopic examination of the flat-embedded vibratome sections of the lumbar spinal cord showed anterograde WGA-HRP labeling bilaterally, with a clear ipsilateral predominance. Most labeling was seen in the motoneuronal cell groups in the ventral horn (see also Holstege, 1987), in the area around the central canal, and to a lesser extent, in the intermediate zone. Some labeling was also present in the deeper layers of the dorsal horn, and a few fibers were seen in lamina I. Several retrogradely labeled cells were seen on the contralateral side. These were present mainly in lamina $X$ (around the central canal) and the adjacent parts of lamina VII and VIII, as well as dispersed in lamina IV, V, and VI. On the ipsilateral side, a few (between 1 and 4) retrogradely labeled cells were usually present. In these cases, the cells were located either in lamina V, medially in lamina VII, in lamina VIII, and occasionally, in lamina I. Vibratome sections with retrogradely labeled cells in the direct vicinity of the lateral motoneuronal cell groups were rare. These sections were never used for ultrastructural analysis. In the white matter, labeled fibers were observed on the ipsilateral side primarily in the dorsolateral funiculus and, to a lesser extent, in the lateral and ventral funiculi. Some scattcred labeling was seen in the contralateral funiculi. The dorsal funiculi, including the area of the pyramidal tract fibers, were devoid of labeling.

Examination of the ultrathin sections showed that several structures in the lateral motoneuronal cell groups were labeled with $\mathrm{TMB} / \mathrm{DAB}$-cobalt reaction product, indicating that they contained the transported WGA-HRP. Most of the labeled structures were terminals, myelinated and unmyelinated axons, and a few dendritic profiles or structures that could not be identified. This distribution of the labeling was similar to that in a 


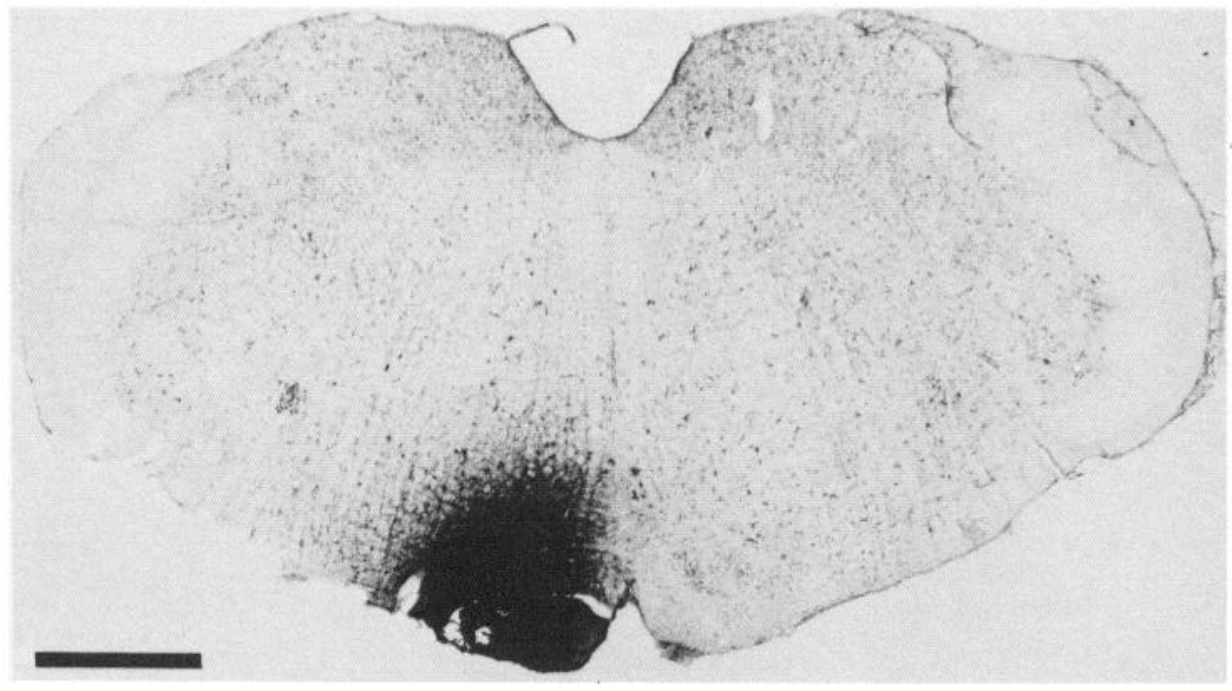

Figure 1. Light micrograph of WGAHRP injection site in ventromedial part of rat lower brain stem at level of rostral inferior olive. Scale bar, $1 \mathrm{~mm}$. previous study (Holstege, 1987). In addition to the WGA-HRPlabeled structures, there were several structures that carried a large number of gold particles, indicating the presence of GABA. The labeling for GABA was confined to terminals and a few myelinated and unmyelinated axons, which is in agreement with previous findings (Holstege and Calkoen, 1990). The gold particles appeared to be distributed randomly over the vesicles within the various GABA-labeled terminal profiles. However, mitochondria often carried a relatively large number of gold particles, possibly because they play a role in the synthesis of GABA from L-glutamate (Roberts, 1987). This may also explain the finding that mitochondria in profiles, which were considered not to be GABAergic, sometimes carried 1 or 2 gold particles.

The analysis in the present study was focused on the WGAHRP-labeled terminal profiles. Three different types of terminals were labeled (Table 1): $57 \%$ were F-type terminals, characterized by their content of mostly flattened vesicles and a few, generally small, spherical vesicles. They usually established symmetric synapses (Figs. 2, 3A, 4A). G-type terminals, characterized by the presence of a large number of dense-cored (granular) vesicles (Fig. $3 B$ ), were labeled in $22 \%$ of the cases. These terminals were seldom seen to establish a synaptic contact in single thin sections (cf. Holstege and Kuypers, 1987a,b). If a synapse was present, it was generally asymmetric. S-type terminals constituted $20 \%$ of the WGA-HRP-labeled terminal profiles (Fig. $4 B$ ) and were characterized by their content of many spherical vesicles. These terminals generally showed asymmet-
Table 1. Quantitative analysis of the labeled terminals in the lateral motoneuronal cell groups of the lumbar 5th and 6th spinal segments after a WGA-HRP injection in the ventromedial lower brain stem and postembedding immunocytochemistry for GABA

\begin{tabular}{|c|c|c|c|c|c|c|}
\hline \multirow{2}{*}{$\begin{array}{l}\text { Type } \\
\text { of ter- } \\
\text { minal }\end{array}$} & \multirow{2}{*}{$\begin{array}{l}\text { Percentage } \\
\text { of all } \\
\text { WGA-HRP- } \\
\text { labeled } \\
\text { terminals }\end{array}$} & \multirow{2}{*}{$\begin{array}{l}\text { Percentage } \\
\text { double } \\
\text { labeled }\end{array}$} & \multirow{2}{*}{$\begin{array}{l}\text { Percentage } \\
\text { showing } \\
\text { synapse }\end{array}$} & \multicolumn{3}{|c|}{$\begin{array}{l}\text { Postsynaptic } \\
\text { structure }\end{array}$} \\
\hline & & & & $\overline{\mathrm{pD}}$ & $\mathrm{dD}$ & CS \\
\hline $\mathrm{F}$ & $57 \pm 6$ & $55 \pm 6$ & $53 \pm 9$ & 72 & 19 & 9 \\
\hline G & $22 \pm 6$ & $23 \pm 10$ & 12 & 67 & 33 & - \\
\hline$S$ & $20 \pm 3$ & $15 \pm 6$ & 39 & 100 & - & - \\
\hline $\mathrm{C}$ & $1 \pm-$ & - & - & - & - & - \\
\hline
\end{tabular}

This table indicates the percentages $( \pm \mathrm{SD})$ of all WGA-HRP-labeled terminals that were F-, G-, S-, or C-type; the percentages of the different types of terminals that were double labeled for WGA-HRP and GABA; the percentages of the different types of double-labeled terminals that established a synaptic contact; and the percentages of their postsynaptic structures. $\mathrm{pD}$, proximal dendrite; $\mathrm{dD}$, distal dendrite; CS, cell soma.

ric synapses with a somewhat wider synaptic cleft. On 3 occasions, a labeled C-type terminal (associated with a subsynaptic cistern in the postsynaptic structure) was observed $(0.6 \%)$. These results were similar to our previous studies on the same system (Holstege, 1987; Holstege and Kuypers, 1987a). A further analysis of the WGA-HRP-labeled terminals showed that $39 \%$ were also labeled for GABA (double labeled). When considering the

Figure 2. Electron micrograph from L5 lateral motoneuronal cell groups, showing several terminal profiles around proximal dendrite (containing ribosomes). Based on the morphology of the synaptic vesicles and synaptic junctions, the different terminals were classified as $F$-type ( $F$; many flattened vesicles and a symmetric synapse) or S-type ( $S$; many spherical vesicles and an asymmetric synapse). The terminal on the left is double labeled with WGA-HRP reaction products, transported from the brain stem injection site (arrows) and with many gold particles (small black dots), indicating the presence of GABA. Arrowheads point at symmetric synapses. Note that the small F-type terminal $(F)$ with the asterisk on the side is strongly labeled for GABA, but does not contain WGA-HRP reaction products. Scale bar, $0.5 \mu \mathrm{m}$.

Figure 3. Electron micrographs from L5 lateral motoneuronal cell groups, showing terminal profiles double labeled with WGA-HRP reaction products (arrows in $A$ ) and many gold particles, indicating that terminals originated from ventromedial reticular formation and contained GABA as transmitter. $A$, A large F-type terminal profile $(F)$ is double labeled and may display 2 (tangentially cut) synaptic junctions. $B$, A G-type terminal profile $(G)$ containing many granular vesicles (small arrows) is double labeled. Because G-type terminals are generally considered to be serotonergic (see Discussion), the labeled G-type terminal may contain both GABA and serotonin. Note that there is an unlabeled F-type terminal profile ( $F$ ) on the right. Scale bars, $0.5 \mu \mathrm{m}$. 


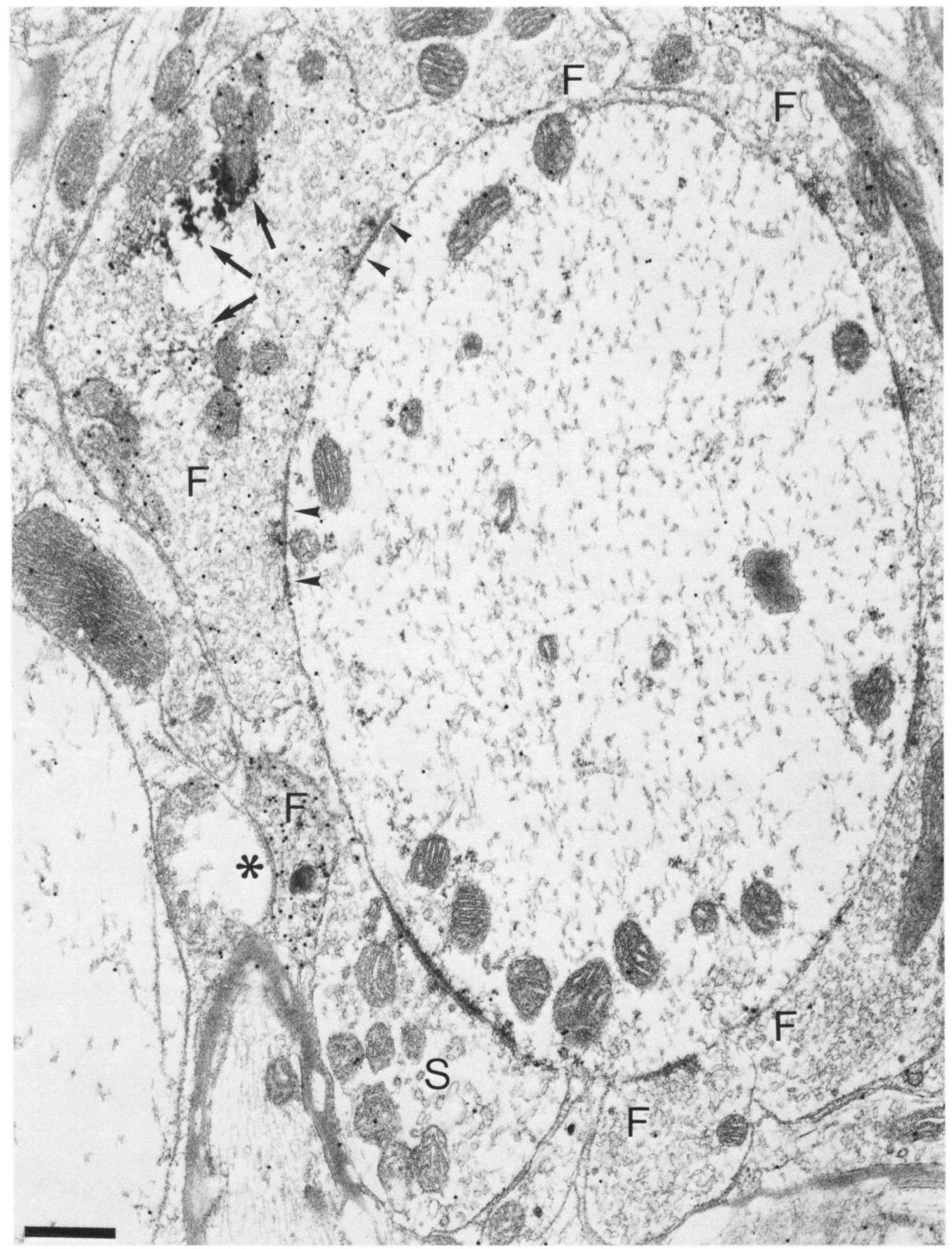



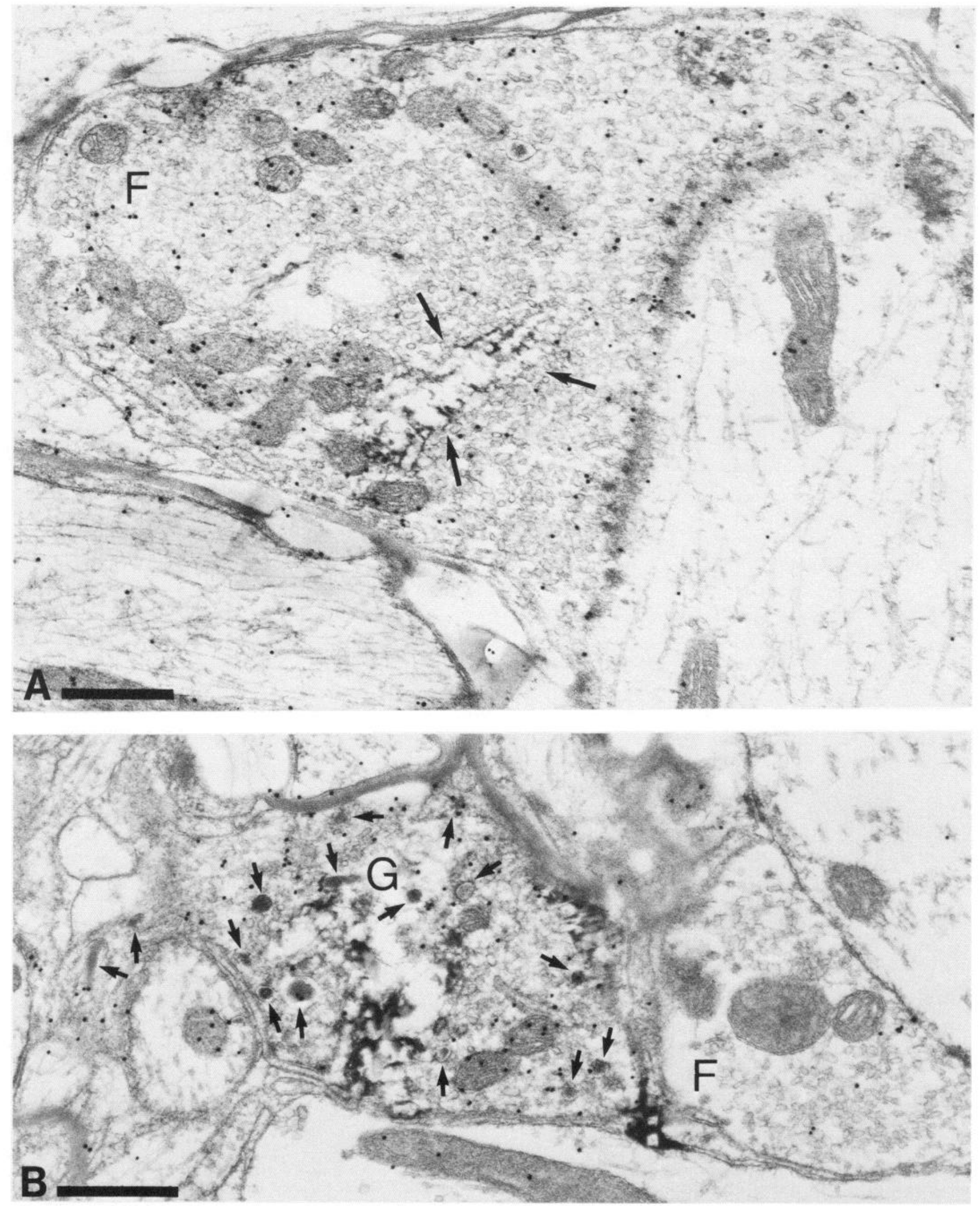

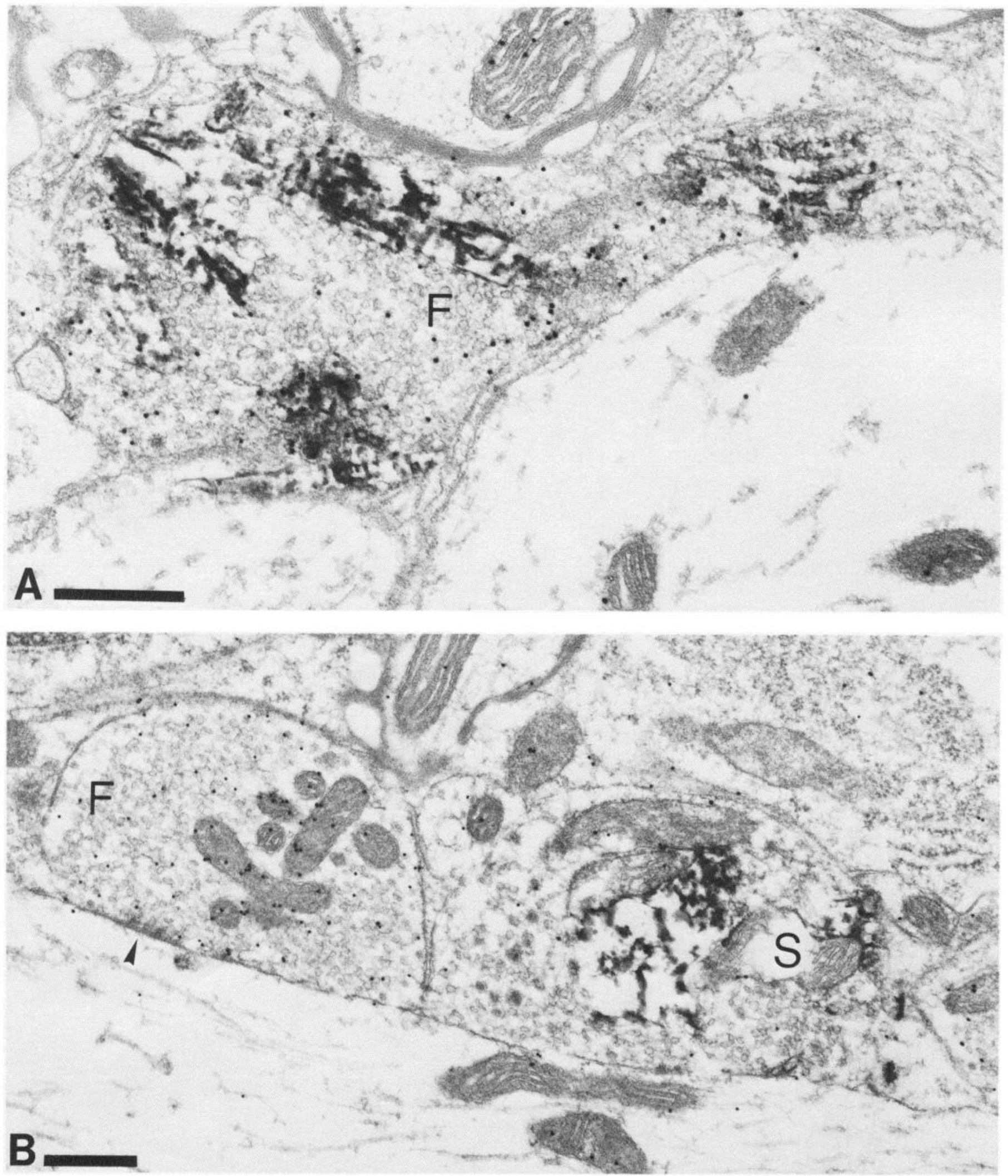

Figure 4. A, Electron micrograph of the L6 lateral motoneuronal cell groups showing an F-type terminal profile $(F)$, double labeled with a large amount of WGA-HRP reaction products and with many gold particles, indicating that the terminal originated from the ventromedial reticular formation and contained GABA as a transmitter. A synaptic junction is not present. $B$, Electron micrograph of the L5 lateral motoneuronal cell groups showing a single WGA-HRP-labeled S-type terminal profile $(S)$ on the right, indicating that the terminal is derived from the ventromedial lower brain stem, but it is not GABAergic, because it carries only a few gold particles. On the left, an F-type terminal profile $(F)$ is single labeled with many gold particles, indicating that the terminal is GABAergic, whereas its origin is unknown. The arrowhead points at a symmetric synaptic junction. Scale bars, $0.5 \mu \mathrm{m}$. 
different types of terminals, it was found that $55 \%$ of the WGAHRP-labeled F-type terminals were double labeled. Furthermore, $23 \%$ of the WGA-HRP-labeled G-type terminal profiles and $15 \%$ of the WGA-HRP-labeled S-type terminal profiles were double labeled. When considering only the double-labeled terminal profiles (Fig. 5), it was found that $81 \%$ were F-type (Figs. 2, 3A, 4A), 12\% were G-type (Fig. 3B), and 7\% were S-type. When a double-labeled terminal was observed to establish a synaptic contact (Table 1), it was mainly (73\%) with proximal dendrites (identified by the presence of ribosomes) and, to a much lesser extent (18\%), with distal dendrites. Synaptic contacts with cell somata were seen in 8 cases $(9 \%)$, and in most of these cases, the size of the postsynaptic cell soma was such that it could be classified as an $\alpha$-motoneuron (cf. Strick et al., 1976). Axoaxonic (presynaptic) contacts were never established by any of the WGA-HRP- or double-labeled terminals.

\section{Discussion}

The present data demonstrate that nearly $40 \%$ of the projections from the lower brain stem to spinal motoneuronal cell groups contained GABA as a transmitter. This result was obtained with a new technique that made it possible to demonstrate the presence of a spccific transmitter (GABA) in the terminals of an identified pathway. This technique was tested in our laboratory on afferents of the inferior olive (De Zeeuw et al., 1988). In that study, it was found that virtually all terminals derived from the cerebellar nuclei were GABAergic, while none of the terminals derived from the area of the nucleus of Darkschewitsch were labeled for $\mathrm{GABA}$. These results demonstrated not only that the GABA labeling was not due to the presence of WGA-HRP reaction products, but also showed the high efficacy of the immunogold technique, because percentages up to nearly $100 \%$ can be obtained. This implies that the $40 \%$ of double labeling obtained in the present study should be regarded not as an underestimate, but as a rather accurate figure.

The results obtained with respect to the different types of WGA-HRP-labeled terminals are similar to the results obtained in previous studies on the same projection system using WGAHRP (Holstcge, 1987) or ${ }^{3} \mathrm{H}$-leucine (Holstege and Kuypers, 1987a), which is not transported retrogradely. In the present study, it cannot be excluded that some of the labeled terminals belonged to collateral axons of retrogradely labeled cells that were observed on the ipsilateral side in the vibratome sections. However, their number was much too small ( $0-4$ cells per section) to significantly influence the results.

It is assumed that the GABAergic brain stem fibers contact spinal motoneurons and not, or much less, interneuronal dendrites within the spinal motoneuronal cell groups. This assumption is based on the following considerations. First, we have demonstrated in a previous study (Holstege and Kuypers, 1987a), by combining the anterograde transport of ${ }^{3} \mathrm{H}$-leucine from neurons in the lower brain stem with the retrograde transport of HRP from the hindleg muscles, that the majority of the ${ }^{3} \mathrm{H}$-leucine-labeled terminals actually contacted HRP-labeled motoneurons in the lumbar spinal cord. Second, it was found in the cat that interneurons generally have few dendrites, and only their distal parts are located within the motoneuronal cell groups (Jankowska and Lindström, 1972; Lagerbäck and Kellerth, 1985). If this would also apply to the rat, it seems most likely that the proximal dendrites, which are the main target of the GABAergic terminals, belonged to motoneurons. The finding (Holstege and Calkoen, 1990) that the motoneuronal cell
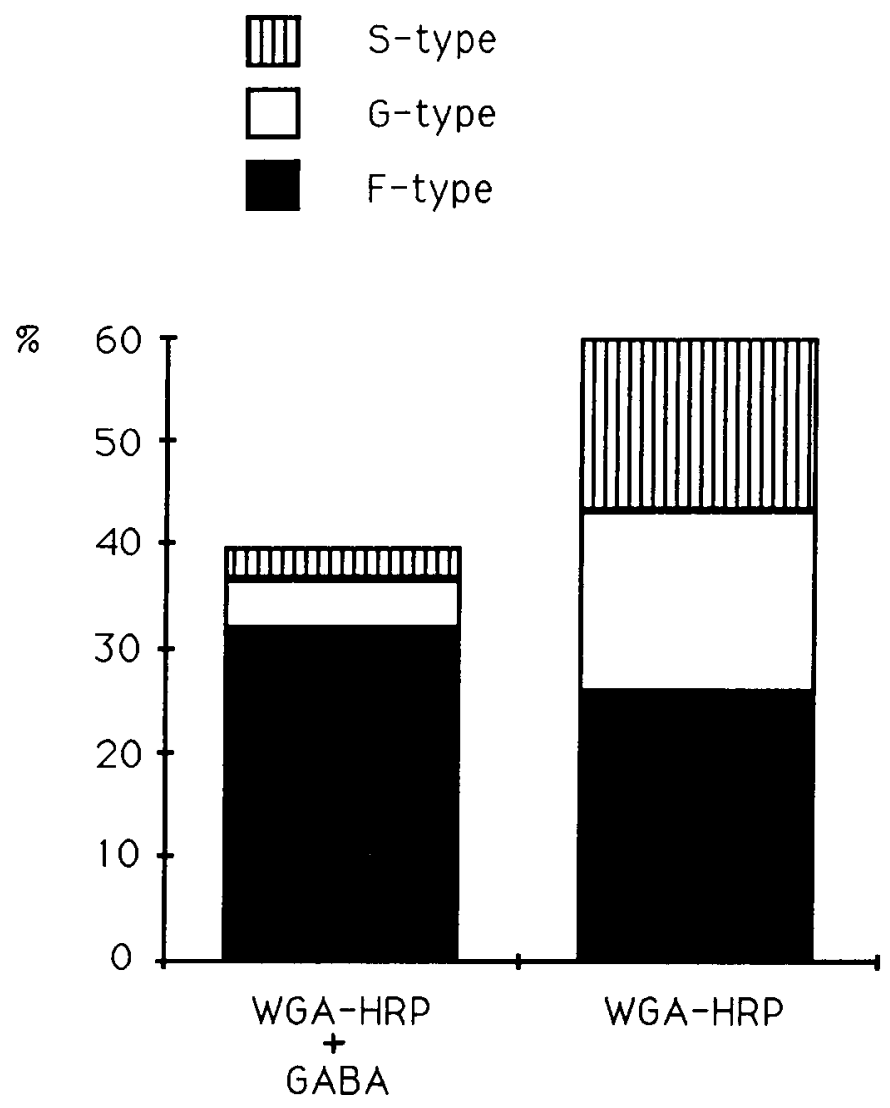

Figure 5. Histogram showing percentages of all terminals, labeled with WGA-HRP from ventromedial lower brain stem, that were GABAergic (left column) or non-GABAergic (right column). Within these populations, the frequency of the $F$-, $G$ - and $S$-types of terminals is indicated.

groups contain very few GABAergic dendrites also indicates that there are few dendrites belonging to GABAergic interneurons in the motoneuronal cell groups. Moreover, a few of the double-labeled terminals were found to contact large (motoncuronal) somata.

The analysis of the double-labeled terminals showed that the majority were F-type terminals, in agreement with preembedding immunocytochemical studies on the distribution of GABA in motoneuronal cell groups of the spinal cord (McLaughlin et al., 1975; Holstege and Calkoen, 1990) and brain stem (Takasu et al., 1987). The fact that not all of the WGA-HRP-labeled F-type terminals were labeled for GABA suggests, especially in view of the high sensitivity of the immunogold technique, that another transmitter is present in these terminals. F-type terminals in the motoneuronal cell groups have been shown to contain not only GABA, but also glycine (Matus and Dennison, 1971; Ljungdahl and Hökfelt, 1973; Van den Pol and Gorcs, 1988). Therefore, glycine may also be present in the descending projections from the lower brain stem. Preliminary data, which we have recently obtained (Holstege and Bongers, 1990), indicate that this is indeed the case. The present results further showed that a limited number of G-type terminals were double labeled. Because G-type terminals in the spinal motoneuronal cell groups have been shown to be serotonergic and/or peptidergic (Pelletier et al., 1981; Ulfhake et al., 1987), the present findings suggest that GABA and serotonin are colocalized in some of the G-type terminals derived from the lower brain stem. This is in agreement with studies showing colocalization of GABA 
and serotonin in neurons of the raphe nuclei and the adjoining reticular formation, including those that project to the spinal cord (Millhorn et al., 1987).

The anatomical findings reported here on the existence of a GABAergic (inhibitory) projection to spinal motoneurons are in agreement with the early electrophysiological findings of Magoun and Rhines (1946). They were able to evoke monosynaptic inhibitory potentials in spinal motoneurons from an area in the ventromedial part of the lower brain stem, now generally known as the "inhibitory center of Magoun." Because its location in the lower brain stem of the cat largely coincides with the WGAHRP injection of the present study, the present findings may provide the anatomical substrate for this inhibitory center and, further, show that GABA is used as an (inhibitory) transmitter. For the functional interpretation of this inhibitory brain stem projection to spinal motoneurons, it is important to note that the GABAergic terminals from the lower brain stem were randomly distributed over the motoneuronal cell groups, without a clear preference for flexor or extensor motoneuron groups (cf. J. C. Holstege and Kuypers, 1982). The high degree of collateralization in this descending brain stem system (Martin et al., 1981; Huisman et al., 1984) is in agreement with its rather diffuse projection. Hence, it seems likely, from an anatomical point of view, that the descending GABAergic projection exerts a general inhibitory role, decreasing the excitability of the spinal motoneurons. In this respect, it would counteract the role of serotonin, which in all likelihood facilitates the excitability of motoneurons (Cardona and Rudomin, 1983; Roberts et al., 1988; Fung and Barnes, 1989; for review, see Holstege and Kuypers, 1987b).

Spinal motoneurons display a bistable behavior (Hounsgaard et al., 1984); that is, the motoneurons can be "switched" between 2 levels of excitability. Subsequent studies (Crone et al., 1988; Hounsgaard et al., 1988) have shown that the higher level of excitability could be triggered by short-lasting excitation, whereas short inhibitory impulses could reset the excitability of the motoneurons to its "normal" level. These phenomena disappeared after spinal transection, but reappeared following intravenous injection of the serotonin precursor 5-hydroxytryptophan, suggesting that the presence of descending serotonergic afferents was essential for the occurrence of bistable behavior in motoneurons. Because the resetting of motoneurons to their normal level could be produced by short, inhibitory impulses elicited with medial brain stem stimulation (Crone et al., 1988), it may be speculated that the GABAergic projections to spinal motoneurons are instrumental in achieving this effect. This would imply that the activity in the GABAergic fibers may determine the effectiveness of the serotonergic projection and, as a consequence, the level of excitability of the motoneurons in the spinal cord. The finding of the present study, that GABA is located in presumed serotonergic terminals in the motoneuronal cell groups, and the finding (Nicoll, 1988) that, at least in hippocampus, the GABA receptor and the $5 \mathrm{HT}-1 \mathrm{~A}$ receptor are linked to the same ion channel emphasize the intimate relation betwecn scrotonin and GABA in the descending projections to spinal motoneurons.

The area in the lower brain stem from which the GABAergic fibers originate has also been implicated in the inhibition of motoneurons during REM sleep, a sleep phase during which there exists complete muscle atonia (see, e.g., Siegel, 1989). In this state, it is to be expected that the balance between the serotonergic and the GABAergic fibers is shifted to the GABAergic side with complete inactivity of the serotonergic fibers.
Recordings from serotonergic neurons in the caudal raphe nuclei (Heym et al., 1982; Trulson and Trulson, 1982) indeed showed that these neurons are silent during active sleep and become increasingly active when the animal passes through the various states of sleep towards quiet and active waking. Recordings from motoneurons in unrestrained cats during sleep and wakefulness (Soja et al., 1987) have shown that glycine may act as the transmitter in the projections mediating muscle atonia during active sleep. This seems in contradiction with the present finding that GABA is present in the descending projections from the lower brain stem. However, this contradiction may be more apparent than real, because the present findings leave room for the presence of glycine in the non-GABAergic F-type terminals derived from the lower brain stem. It may thus be hypothesized that the presumed glycinergic part of this system would be especially active during REM sleep, whereas the GABAergic system would be active during other states of sleep and "relaxed states" of wakefulness.

The present data are the first anatomical evidence for the existence of a GABAergic system projecting directly from the ventromedial brain stem to spinal motoneurons. These projections, which apparently terminate directly and nonselectively on motoncurons, may subscrve a gencral inhibitory role, controlling the excitability of the spinal motoneurons. In addition to the GABA-containing fibers, there are also fibers (derived from the same brain stem area) that contain serotonin with various peptides, and possibly glycine and $\mathrm{ACh}$. A further understanding of how these various transmitters interact would give more insight in the regulation of motor behavior during sleep and wakefulness.

\section{References}

Andrezik JA, Beitz AJ (1985) Reticular formation, central grey and related tegmental nuclei. In: The rat nervous system, Vol 2, Hindbrain and spinal cord (Paxinos G, ed), pp 1-28. London: Academic.

Bowker RM, Westlund KN, Sullivan MC, Wilber JF, Coulter JD (1983) Descending serotonergic, peptidergic and cholinergic pathways from the raphe nuclei. A multiple transmitter complex. Brain Res 288:3348.

Brodal P, Dietrichs JG, Bjaalie T, Nordby T, Walberg F (1983) Is lectin-coupled horseradish peroxidase taken up and transported by damaged as well as by undamaged fibers in the central nervous system? Brain Res 278:1-9.

Buijs RM, van Vulpen EHS, Geffard M (1987) Ultrastructural localization of GABA in the supraoptic nucleus and neural lobe. Neuroscience 20:347-355.

Cardona A, Rudomin P (1983) Activation of brainstem serotonergic pathways decreases homosynaptic depression of monosynaptic responses of frog spinal motoneurons. Brain Res 280:373-378.

Crone C, Hultborn H, Kiehn O, Mazieres L, Wigstrom H (1988) Maintained changes in motoneuronal excitability by short-lasting synaptic inputs in the decerebrate cat. J Physiol (Lond) 405:321-343.

Dahlström A, Fuxe K (1965) Evidence for the existence of monoamine neurons in the central nervous system. II. Experimentally induced changes in the intraneuronal amine levels of bulbospinal neuron systems. Acta Physiol Scand [Suppl 64] 247:6-36.

De Zeeuw CI, Holstege JC, Calkoen F, Ruigrok TJH, Voogd J (1988) A new combination of WGA-HRP anterograde tracing and GABAimmunocytochemistry applied to afferents of the cat inferior olive at the ultrastructural level. Brain Res 447:369-375.

Fung SJ, Barnes CD (1989) Raphé-produced excitation of spinal cord motoncurons in the cat. Ncurosci Lett 103:185-190.

Graham RC, Karnovsky MJ (1966) The early stages of absorption of injected horseradish peroxidase in the proximal tubules of the mouse kidney. Ultrastructural cytochemistry by a new technique. J Histochem Cytochem 14:291-302.

Heym J, Steinfels GF, Jacobs BL (1982) Activity of serotonin-containing neurons in the nucleus raphe pallidus of freely moving cats. Brain Res 251:259-276. 
Hökfelt T, Terenius L, Kuypers HGJM, Dann O (1979) Evidence for enkephalin immunoreactive neurons in the medulla oblongata projecting to the spinal cord. Neurosci Lett 14:55-60.

Holstege G, Kuypers HGJM (1982) The anatomy of brain stem pathways to the spinal cord in cat. A labelled amino acid tracing study. In: Progress in brain research, Vol 57, Descending pathways to the spinal cord (Kuypers HGJM, Martin GF, eds), pp 177-183. Amsterdam: Elsevier.

Holstege G, Kuypers HGJM, Boer RC (1979) Anatomical evidence for direct brain stem projections to the somatic motoneuronal cell groups and autonomic preganglionic cell groups in cat spinal cord. Brain Res 171:329-333.

Holstege JC (1987) Brainstem projections to lumbar motoneurons in rat-II. An ultrastructural study by mcans of the anterograde transport of wheat-germ agglutinin coupled to horseradish peroxidase and using the tetramethyl benzidine reaction. Neuroscience 21:369-376.

Holstege JC, Bongers CMH (1990) Ultrastructural evidence that brainstem projections to spinal motoneurons contain glycine. Eur J Neurosci Suppl 3:96.

Holstege JC, Calkoen F (1990) The distribution of GABA in lumbar motoneuronal cell groups. A quantitative ultrastructural study in rat. Brain Res 530:130-137.

Holstege JC, Kuypers HGJM (1982) Brain stem projections to spinal motoneuronal cell groups in rat studied by means of electron microscopy autoradiography. In: Progress in brain research, Vol 57, Descending pathways to the spinal cord (Kuypers HGJM, Martin GF, eds), pp 177-183. Amsterdam: Elsevier.

Holstege JC, Kuypcrs HGJM (1987a) Brainstem projections to lumbar motoneurons in rat $-I$. An ultrastructural study using autoradiography and the combination of autoradiography and HRP histochemistry. Neuroscience 21:345-367.

Holstege JC, Kuypers HGJM (1987b) Brainstem projections to spinal motoneurons: an update. Neuroscience 23:809-821.

Hounsgaard J, Hultborn H, Jespersen B, Khien O (1984) Intrinsic membrane properties causing a bistable behaviour of $\alpha$-motoneurons. Exp Brain Res 55:391-394.

Hounsgaard J, Hultborn H, Jespersen B, Khien O (1988) Bistability of alpha-motoneurons in the decerebrate cat and in the acute spinal cat after intravenous 5-hydroxytryptophan. J Physiol (Lond) 405: 345-367.

Huisman AM, Ververs B, Cavada C, Kuypers HGJM (1984) Collateralization of brainstem pathways in the spinal ventral horn in rat as demonstrated with the retrograde fluorescent double-labeling technique. Brain Res 300:362-367.

Jankowska E, Lindström S (1972) Morphology of interneurons mediating Ia reciprocal inhibition of motoneurons in the spinal cord of the cat. J Physiol (Lond) 226:805-823.

Jones BE, Yang T-Z (1985) The efferent projections from the reticular formation and the locus coeruleus studied by anterograde and retrograde axonal transport in rat. J Comp Neurol 242:56-92

Jones BE, Pare M, Beaudet A (1986) Retrograde labeling of neurons in the brain stem following injections of $\left[{ }^{3} \mathrm{H}\right]$ choline into the rat spinal cord. Neuroscience 18:901-916.

Krnjévic K, Schwartz S (1966) Is gamma-aminobutyric acid an inhibitory transmitter? Nature 211:1372-1374.

Kuypers HGJM (1981) Anatomy of the descending pathways. In: Handbook of physiology, the nervous system, Vol II, Motor control, Pt I (Brookhart JM, Mountcastle VB, Brooks VB, Geiger SR, eds), pp 667-702. Bethesda: American Physiological Society.

Lagerbäck P-A, Kellerth J-O (1985) Light microscopic observations on cat Renshaw cells after intracellular staining with horseradish peroxidase. II. The cell bodies and dendrites. J Comp Neurol 240:368376.

Lemann W, Saper CB, Rye DB, Wainer BH (1985) Stabilization of TMB reaction product for electron microscopic retrograde and anterograde fiber tracing. Brain Res Bull 14:277-281.

Ljungdahl A, Hökfelt T (1973) Autoradiographic uptake patterns of ${ }^{3} \mathrm{H}-\mathrm{GABA}$ and ${ }^{3} \mathrm{H}$-glycine in central nervous tissues with special reference to the cat spinal cord. Brain Res 62:587-595.

Llinas R, Terzuolo CA (1964) Mechanisms of supraspinal actions upon spinal cord activities. Reticular inhibitory mechanisms on alpha-cxtcnsor motoneurons. J Neurophysiol 27:579-591.

Magoun HW, Rhines R (1946) An inhibitory mechanism in the bulbar reticular formation. J Neurophysiol 9:165-171.

Mantyh PW, Hunt SP (1984) Evidence for cholecystokinin-like im- munoreactive neurons in the rat medulla oblongata which project to the spinal cord. Brain Res 291:49-54.

Martin GF, Humbertson AO, Laxson LS, Panneton WM, Tschismadia I (1979) Spinal projections from mesencephalic and pontine reticular formation in North American opossum: a study using axonal transport techniques. J Comp Neurol 187:373-400.

Martin GF, Cabana T, Humbertson AO (1981) Evidence for collateral innervation of the cervical and lumbar enlargements of the spinal cord by single reticular and raphe neurons. Studies using fluorescent markers in double-labeling experiments on the North American opossum. Neurosci Lett 24:1-6.

Martin GF, Vertes RP, Waltzer R (1985) Spinal projections of the gigantocellular reticular formation in the rat. Evidence for projections from different areas to lamina I and II and lamina IX. Exp Brain Res 58:154-162.

Matus AI, Dennison ME (1971) Autoradiographic localisation of tritiated glycine at "flat-vesicle" synapses in spinal cord. Brain Res 32: 195-197.

McLaughlin BJ, Barber R, Saito K, Roberts E, Wu J-Y (1975) Immunocytochemical localization of glutamate decarboxylase in the rat spinal cord. J Comp Neurol 164:305-322.

Mesulam M-M (1978) Tetramethyl benzidine for horseradish peroxidase neurohistochemistry: a non-carcinogenic blue reaction-product with superior sensitivity for visualizing neural afferents and efferents. J Histochem Cytochem 26:106-117.

Millhorn DE, Hökfelt T, Seroogy K, Oertel W, Verhofstad AAJ, Wu J-Y (1987) Immunohistochemical evidence for colocalisation of $\gamma$-aminobutyric acid and serotonin in neurons of the ventral medulla oblongata projecting to the spinal cord. Brain Res 410:179-185.

Muller LL, Jacks TJ (1975) Rapid chemical dehydration of samples for electron microscopic examinations. J Histochem Cytochem 23: 107-110.

Nicoll RA (1988) The coupling of neurotransmitter receptors to ion channels in the brain. Science 241:545-551.

Pelletier G, Steinbusch HWM, Verhofstad AAJ (1981) Immunoreactive substance $P$ and serotonin present in the same dense-core vesicles. Nature 293:71-72.

Roberts E (1987) Gamma-aminobutyric acid (GABA). In: Encyclopedia of neuroscience (Edelman G, ed), pp 441-444. Boston: Birkhäuser.

Roberts MH, Davies M, Girdlestone D, Foster GA (1988) Effects of 5-hydroxytryptamine agonists and antagonists on the responses of rat spinal motoneurons to raphe obscurus stimulation. Br J Pharmacol 95:437-448.

Seguela P, Geffard M, Buijs RM, Le Moal M (1984) Antibodies against gamma-aminobutyric acid: specificity studies and immunocytochemical results. Proc Natl Acad Sci USA 81:3888-3892.

Siegel JM (1989) Brainstem mechanisms generating REM sleep. In: Principles and practice of sleep medicine (Kryger MH, Roth T, Dement WC, eds), pp 104-120. Philadelphia: Saunders.

Soja PJ, Morales FR, Baranyi A, Chase MH (1987) Effect of inhibitory amino acid antagonists on IPSPs induced in lumbar motoneurons upon stimulation of the nucleus reticularis gigantocellularis during active sleep. Brain Res 423:353-358.

Strick PL, Burke RE, Kanda K, Kim CC, Walmsley B (1976) Difference between alpha and gamma motoneurons labeled with horseradish peroxidase by retrograde transport. Brain Res 113:582-588.

Takasu N, Nakatani T, Arikuni T, Kimura H (1987) Immuno-cytochemical localization of gamma-aminobutyric acid in the hypoglossal nucleus of the macaque monkey, Macaca fuscata: a light and electron microscopic study. J Comp Neurol 263:42-53.

Trulson ME, Trulson VM (1982) Activity of nucleus raphe pallidus neurons across the sleep-waking cycle in freely moving cats. Brain Res 237:232-237.

Ulfhake B, Arvidsson U, Cullheim S, Hökfelt T, Brodin E, Verhofstad $A$, Visser T (1987) An ultrastructural study of 5-hydroxytryptamine-, thyrotropin-releasing hormone- and substance $P$-immunoreactive axonal boutons in the motor nucleus of spinal cord segments L7-S1 in the adult cat. Neuroscience 23:917-929.

Van den Pol AN, Gorcs T (1988) Glycine and glycine receptor immunoreactivity in brain and spinal cord. J Neurosci 8:472-492.

Wilson VJ, Peterson BW (1981) Vestibulospinal and reticulospinal systems. In: Handbook of physiology, the nervous system, Vol II, Motor control, Pt I (Brookhart JM, Mountcastle VB, Brooks VB, Geiger SR, eds), pp 667-702. Bethesda: American Physiological Society. 